\title{
Permeability of Natural Rock Salt From the Waste Isolation Pilot Plant (WIPP) During Damage Evolution and Healing
}

\author{
T. W. Pfeifle ${ }^{1}$ and L. D. Hurtado ${ }^{2}$ \\ ${ }^{1} \mathrm{RE} / \mathrm{SPEC}$ Inc. \\ P.O. Box 725, Rapid City, SD USA 57709 \\ ${ }^{2}$ Sandia National Laboratories \\ P.O. Box 5800, Albuquerque, NM USA 87185
}



\section{ABSTRACT}

The U. S. Department of Energy has developed the Waste Isolation Pilot Plant (WIPP) in the bedded salt of southeastern New Mexico to demonstrate the safe disposal of radioactive transuranic wastes. Four vertical shafts provide access to the underground workings located at a depth of about 660 meters. These shafts connect the underground facility to the surface and potentially provide communication between lithologic units, so they will be sealed to limit both the release of hazardous waste from and fluid flow into the repository. The seal design must consider the potential for fluid flow through a disturbed rock zone (DRZ) that develops in the salt near the shafts. The DRZ, which forms initially during excavation and then evolves with time, is expected to have higher permeability than the native salt. The closure of the shaft openings (i.e., through salt creep) will compress the seals, thereby inducing a compressive back-stress on the DRZ. This back-stress is expected to arrest the evolution of the DRZ, and with time will promote healing of damage. This paper presents laboratory data from tertiary creep and hydrostatic compression tests designed to characterize damage evolution and healing in WIPP salt. Healing is quantified in terms of permanent reduction in permeability, and the data are used to estimate healing times based on considerations of firstorder kinetics.

\section{KEYWORDS}

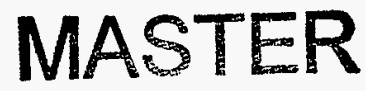

Salt, damage, healing, dilatant volumetric strain, permeability, nuclear waste, WIPP, DRZ

\section{INTRODUCTION}

The U. S. Department of Energy has developed the Waste Isolation Pilot Plant (WIPP) in southeastern New Mexico as a research and development facility for the purpose of demonstrating the safe management, storage, and disposal of radioactive transuranic waste. The underground workings of the WIPP are located in the bedded salt of the Salado Formation at a depth of about 660 meters, and access is provided by four 


\section{DISCLAIMER}

This report was prepared as an account of work sponsored by an agency of the United States Government. Neither the United States Government nor any agency thereof, nor any of their employees, makes any warranty, express or implied, or assumes any legal liability or responsibility for the accuracy, completeness, or usefulness of any information, apparatus, product, or process disclosed, or represents that its use would not infringe privately owned rights. Reference herein to any specinic commercial product, process, or service by trade name, trademark, manufacturer, or otherwise does not necessarily constitute or imply its endorsement, recommendation, or favoring by the United States Government or any agency thereof. The views and opinions of authors expressed herein do not necessarily state or reflect those of the United States Government or any agency thereof. 
vertical shafts having diameters that vary from 3 meters to 6 meters. The shafts connect the underground facility to the surface and potentially provide communication between lithologic units, so they will be sealed to limit the release of hazardous waste from and fluid flow into the repository after decommissioning.

The excavation of each shaft produces high deviatoric stresses in the salt near the shaft opening because of the stress-concentrating effect of the opening itself. Field and laboratory evidence (Dale and Hurtado, 1996; Pfeifle et al, 1998) suggest that the deviatoric stresses produce a disturbed rock zone (DRZ) in the salt near each shaft immediately after excavation and that this zone evolves with time through a damage process known as stress-induced microfracturing. The DRZ is expected to have higher permeability than the native salt because of this damage. After the shaft seals are emplaced, compressive back-stresses will develop in the seal materials as the shaft closes by virtue of salt creep. These compressive back-stresses act to reduce the relatively high deviatoric stresses in the salt and will, eventually, return the stress state in the DRZ to a lithostatic (hydrostatic) condition; i.e., the stress state that existed before the shafts were excavated.

The back-stress induced by the seals is expected to promote healing in the DRZ. For example, Brodsky (1990) investigated healing of WIPP salt in which specimens were damaged in a series of quasi-static constant strain-rate laboratory tests and then subjected to hydrostatic compression stages of either 5,10 , or $15 \mathrm{MPa}$. Compressional wave velocity and attenuation measurements were made with time to monitor the healing process. Results showed that healing (i.e., the restoration of the original wave velocity and attenuation characteristics of the undamaged salt) occurred under the hydrostatic stress conditions imposed during the test; however, the effect of healing on permeability reduction was not investigated. Knowledge of the damage evolution and healing processes of WIPP salt, as well as how these processes affect permeability, is critically important to the evaluation of the WIPP shaft seals. Therefore, the objective of this paper is to present laboratory data for clean and argillaceous WIPP salt that characterize both damage evolution and subsequent healing. Additionally, data are presented for permeability measurements performed on salt specimens immediately after damage was induced and also during healing under hydrostatic conditions. These data were used to estimate healing times based on considerations of first-order kinetics. The distinction between clean and argillaceous salt was previously based on visual observations. X-ray diffraction analyses of the two salts were performed in this study to quantify differences in mineralogy.

\section{TECHNICAL APPROACH}

Laboratory tests were performed in this study to supplement and extend the damage evolution and permeability data for clean WIPP salt presented by Pfeifle et al (1998). Specifically, laboratory-scale experiments were performed on clean and argillaceous WIPP salt specimens to determine the effects of: (1) salt mineralogy on damage evolution, (2) hydrostatic stress on healing, (3) pore fluid composition on healing, and (4) microfracture-induced damage and healing on permeability.

Damage and healing were quantified using dilatant volumetric strain (assuming salt behaves isochorically under nondamaging stress states) and permanent permeability reduction, respectively. Cylindrical specimens used in the experiments were prepared from clean and argillaceous salt cores recovered from the WIPP workings and were nominally 200 millimeters in length by 100 millimeters in diameter.

Four constant stress triaxial compression creep tests were performed on argillaceous salt specimens at a temperature of $25^{\circ} \mathrm{C}$, a stress difference of $20 \mathrm{MPa}$, and a confining pressure of either 3 or $4 \mathrm{MPa}$. These tests conditions were designed to promote tertiary creep; i.e., accelerating creep resulting from the accumulation of microfracture-induced damage. The tests were terminated before the damage accumulation led to failure (except in one test) by invoking a test termination criterion based on accumulated dilatant volumetric strain. The goal of the criterion was to produce specimens with dilatant volumetric strains ranging between 0 and about 0.5 percent. Following the creep tests, constant head nitrogen gas permeability measurements were made on each damaged specimen except the one that failed during the creep test. All permeability testing was performed using a flexible-wall permeameter pressurized to $1 \mathrm{MPa}$ and a nominal gas 
pressure difference of $0.345 \mathrm{MPa}$ induced across the specimen. The pressure difference was maintained until steady-state flow was observed, where flow was measured using a rotameter flow meter system. Salt mineralogy for each argillaceous salt specimen and four clean salt specimens tested by Pfeifle et al (1998) was determined using X-ray diffraction (XRD) techniques. The XRD data were used to characterize salt mineralogy so that mineralogy could be related to the observed damage.

Eight multistage hydrostatic compression healing tests were performed on WIPP salt, including seven on clean salt specimens damaged by Pfeifle et al (1998) and one on argillaceous salt damaged in this study. Each test comprised one or more stages of healing in which the temperature was $25^{\circ} \mathrm{C}$ and the hydrostatic stress was either $1,5,10$, or $15 \mathrm{MPa}$. Permeability measurements were made during each healing stage using either synthetic brine or nitrogen gas as the permeant. All permeability testing was performed using a flexible-wall permeameter pressurized to $1 \mathrm{MPa}$ as described above and a fluid pressure gradient aligned parallel with the central axis of the specimen. In the tests performed with brine, the nominal fluid pressure difference induced across the specimen was $0.345 \mathrm{MPa}$ and flow rates were measured using a buret located on the downstream side of the specimen. In the tests performed with nitrogen gas, the nominal fluid pressure difference was $0.4 \mathrm{MPa}$ and the flow rates were measured using either a rotameter flow meter or a manometer system. Pressure gradients were maintained until steady-state flow was observed. The data acquired in these tests were fitted by a simple first-order kinetics model to determine time constants for each level of hydrostatic stress and each type of permeant. The time constants were used to quantify the effect of hydrostatic stress and permeant type on healing and also to predict times required for complete healing.

\section{TEST EQUIPMENT AND PROCEDURES}

The test equipment and procedures used to conduct the tertiary creep tests, nitrogen gas permeability measurements, and dilatant volumetric strain determinations were identical to those used by Pfeifle et al (1998). All instrumentation used to collect data were calibrated against standards traceable to the National Institute for Standards and Technology (NIST). Equipment and procedures used for the hydrostatic compression healing tests, the brine permeability measurements, and the XRD analyses are described below.

\section{Hydrostatic Compression Healing Tests}

The multistage hydrostatic compression healing tests employed the same triaxial test system used for the creep tests. A detailed description of this system is provided by Pfeifle et al (1998). The test protocol, including a description of the specimen assembly procedure, is provided below.

Each damaged test specimen was placed between two metal platens equipped with a 5-millimeter-diameter hole or vent drilled coincident with the central axis of each platen. A Viton jacket was placed over the specimen and secured to the platens with lock wire. The jacket protected the specimen from the fluid (silicone oil) used to induce the hydrostatic stress and also adhered tightly to the specimen during testing so that the permeant could not short-circuit the specimen during permeability measurements. A porous-felt metal disk was placed in each specimen/platen interface to ensure uniform gas pressure along the ends of the specimen, and the vents in the metal platens were connected to the permeability systems using high-pressure tubing.

The healing tests were initiated by hydrostatically loading each specimen to $1 \mathrm{MPa}$ followed by the measurement of a baseline permeability value. The specimen was then allowed to heal at the $1 \mathrm{MPa}$ stress for several days (or in some cases, weeks), at which time, another permeability measurement was made. The process was repeated so that a set of permeability versus time values could be acquired for a specific hydrostatic stress. In most cases, the damaged specimens were subjected to more than one stage of healing. In the subsequent stages, the hydrostatic stress was increased to 5,10 , and sometimes $15 \mathrm{MPa}$. Permeability measurements were again made at specified times to obtain additional sets of permeability versus time values at the different hydrostatic stresses. These measurements were made by first unloading the specimen to a 
hydrostatic stress level of $1 \mathrm{MPa}$ and then inducing the fluid pressure gradient across the specimen. This method was used so that direct comparison of the values could be made with the baseline value. Once the permeability measurements were completed, the specimen was reloaded to the hydrostatic stress level specified for the test stage and healing continued until the next permeability measurements were to be performed. Nitrogen gas permeability measurements made with the rotameter flow meter system were conducted both at the current hydrostatic stress level and at the baseline stress level of $1 \mathrm{MPa}$ so that the effects of permanent healing could be distinguished from the effects of elevated hydrostatic stress in which lower permeability values may be observed because of elastic crack closure.

\section{Brine Permeability Measurements}

Brine permeability measurements were performed on two clean WIPP salt specimens jacketed in the manner described in the previous section and saturated with synthetic brine prepared by dissolving finely ground WIPP salt in distilled water. After the specimens were fully saturated, they were placed in a flexible-wall permeameter and connected hydraulically to the permeability system shown in Figure 1 . This system comprises a brine-filled accumulator, a nitrogen supply reservoir, and a graduated buret. To initiate a test, the specimen was first loaded hydrostatically to a stress of $1 \mathrm{MPa}$ by inducing a pressure against the outer surfaces of the jacketed specimen. Then, a brine pressure gradient was induced parallel with the central axis of the specimen by charging the brine-filled accumulator with nitrogen gas from the reservoir. The brine pressure at the specimen inlet was set manually using the regulator valve on the nitrogen supply reservoir and was monitored by a pressure transducer located in the hydraulic line leading to the specimen inlet. Brine flowing through the specimen was measured by a buret located on the downstream side of the specimen. During the test, the pressure gradient, hydrostatic stress, and temperature were maintained constant, and the volume of brine passing through the specimen was measured as a function of time. The test was terminated when the flow rate reached a steady-state value, usually after 50 to 200 milliliters of brine had passed through the specimen. Permeability, $k$, was calculated from the following expression:

$$
k=\frac{\mu Q L}{A\left(P_{i}-P_{e}\right)}
$$

where $\mu$ is the brine viscosity; $Q$ is the brine flow rate; $L$ and $A$ are the specimen length and cross-sectional area, respectively; and $P_{i}$ and $P_{e}$ are the pressures at the specimen inlet and exit, respectively.

\section{$X-R a y$ Diffraction Analysis}

Salt mineralogy was determined for the four argillaceous salt specimens damaged under conditions of tertiary creep in this study and four clean salt specimens damaged by Pfeifle et al (1998). Samples for the XRD analyses were obtained by making two vertical saw cuts that extended through the full height of each specimen to yield a 25 -millimeter-thick slab of salt representative of the original specimen. Each of these slabs was then finely ground and homogenized to produce individual aliquots for use in the XRD analyses.

\section{RESULTS}

\section{Tertiary Creep and Salt Mineralogy}

Four tertiary creep tests were conducted on argillaceous WIPP salt (1) to induce damage levels that were consistent with the damage levels expected to occur in the DRZ around a typical WIPP opening and (2) to characterize the damage evolution process. All tests were conducted at a stress difference of $20 \mathrm{MPa}$, a temperature of $25^{\circ} \mathrm{C}$, and a confining pressure of either 3 or $4 \mathrm{MPa}$. One of the primary objectives of the tests was to induce a dilatant volumetric strain in each test specimen from 0 to 0.5 percent to simulate the damage expected in the DRZ. In two of the tests, this objective was met as shown in Table 1; however, in 
another test (also shown in Table 1), the induced dilatant volumetric strain was nearly 1 percent. Unfortunately, the test on the fourth test specimen was not terminated before failure occurred, so dilatant volumetric strains could not be determined at the end of this test nor could the test specimen be used for subsequent healing and/or permeability testing.

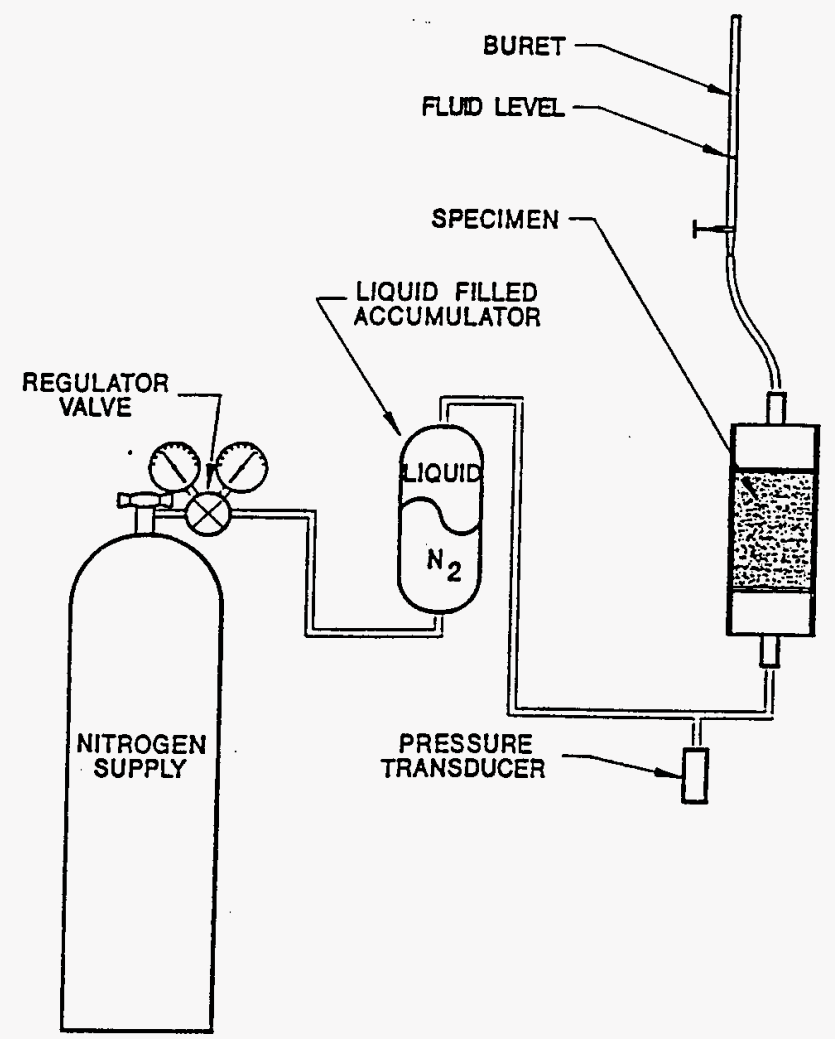

Figure 1: Brine permeability system

TABLE 1

CREEP AND PERMEABILITY RESULTS FOR ARGLLACEOUS WIPP SALT

\begin{tabular}{||c|c|c|c|c|c||}
\hline $\begin{array}{c}\text { Test } \\
\text { I.D. }\end{array}$ & $\begin{array}{c}\text { Confining } \\
\text { Pressure } \\
(\mathrm{MPa}\end{array}$ & $\begin{array}{c}\text { Stress } \\
\text { Difference } \\
(\mathrm{MPa})\end{array}$ & $\begin{array}{c}\text { Temperature } \\
\left({ }^{\circ} \mathrm{C}\right)\end{array}$ & $\begin{array}{c}\text { Dilatant } \\
\text { Volumetric } \\
\text { Strain }\end{array}$ & $\begin{array}{c}\text { Permeability } \\
(\mathrm{a}) \\
\left(\mathrm{m}^{2}\right)\end{array}$ \\
\hline \hline TC53 & 3 & 20 & 25 & 0.0041 & $2.45 \times 10^{-16}$ \\
\hline TC54 & 3 & 20 & 25 & $(\mathrm{~b})$ & $(\mathrm{b})$ \\
\hline TC55 & 3 & 20 & 25 & 0.0100 & $1.19 \times 10^{-13}$ \\
\hline TC56 & 4 & 20 & 25 & 0.0053 & $2.40 \times 10^{-14}$ \\
\hline
\end{tabular}

(a) All flow measurements made with a flow meter.

(b) Specimen failed during creep test.

The axial and radial strain versus time curves for the four tertiary creep tests conducted on argillaceous salt are shown in Figures 2 and 3, respectively. The time and strain scales in these plots have been truncated to make the individual creep curves more distinctive. Figures 2 and 3 also plot the creep curves for four clean WIPP salt specimens tested under conditions identical to those imposed for the argillaceous salt tests. The combined data show that the creep rates and the total creep magnitudes are higher for the argillaceous salt than for the clean salt. The variability in the creep rates and creep magnitudes are also higher among the argillaceous salt specimens than among the clean salt specimens. 


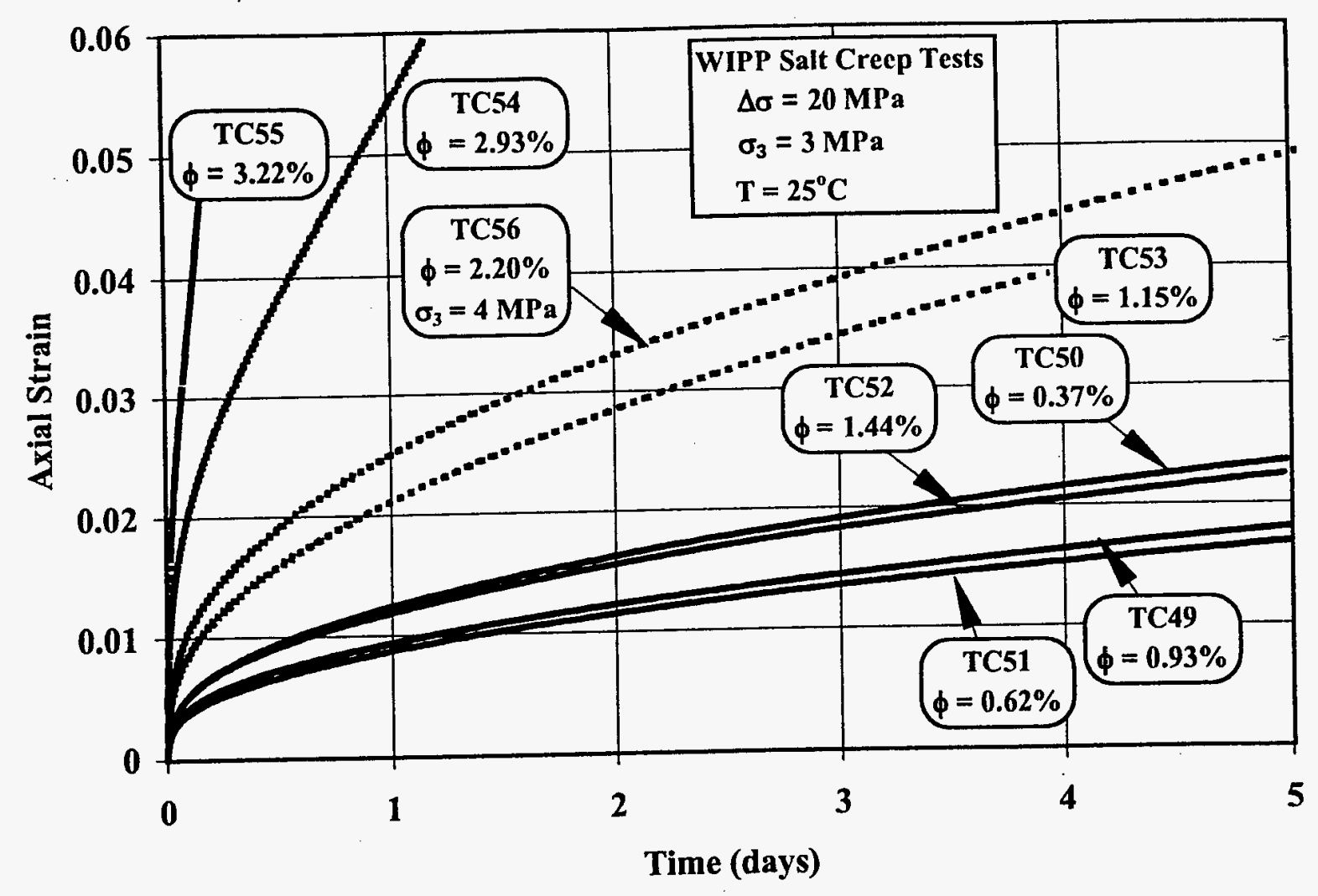

Figure 2: Axial creep strain for clean and argillaceous WIPP salt

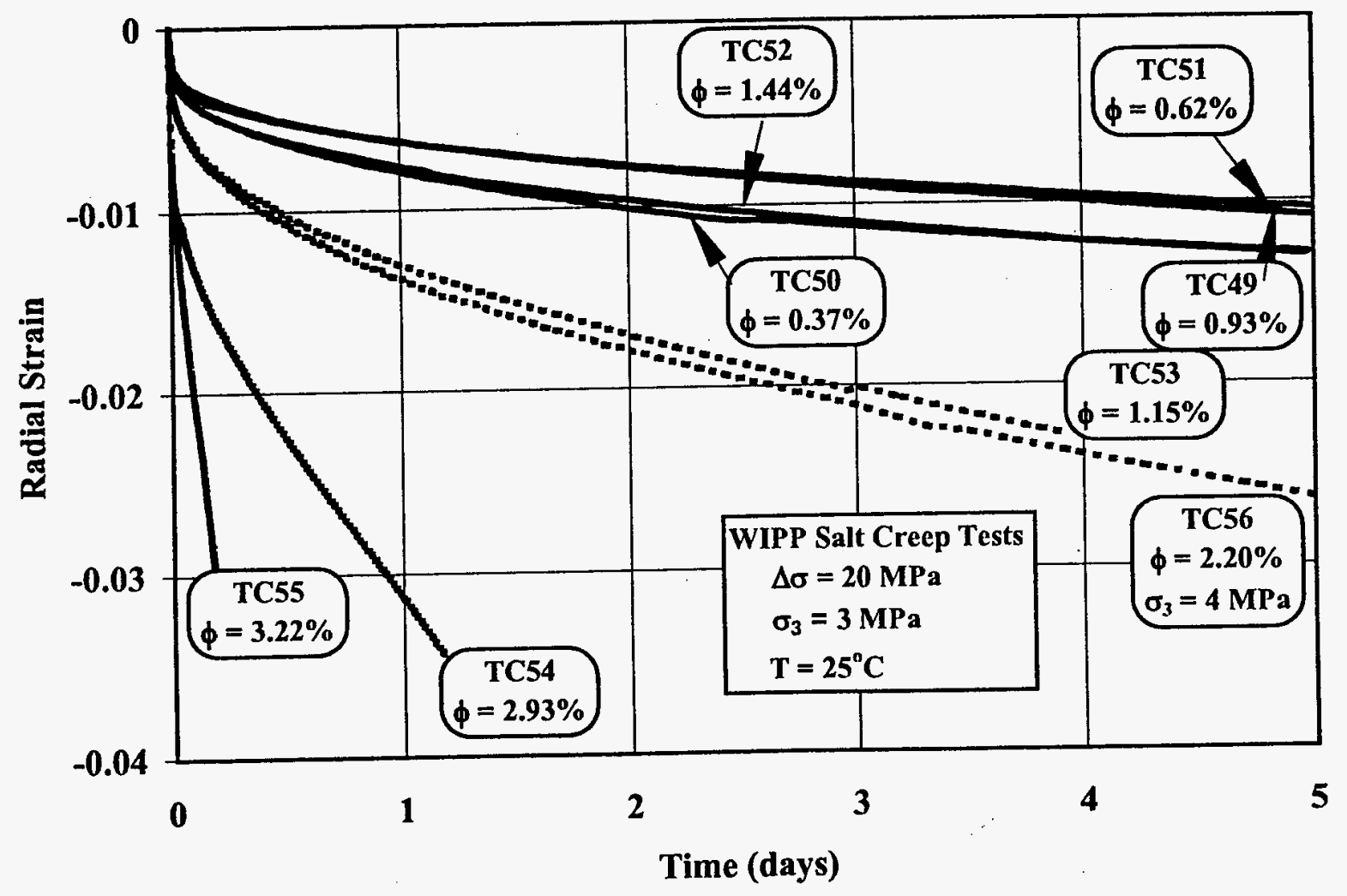

Figure 3: Radial creep strain for clean and argillaceous WIPP salt 
Chan et al (1996) suggest the variability in the deformational behavior of WIPP salt under conditions of tertiary creep is related to the clay content of the salt. That is, enhanced damage and high creep rates are associated with high clay contents because the clay particles are sources for microcrack initiation. The XRD analyses conducted in this study used representative slab samples taken from the central portion of the four clean and four argillaceous salt specimens shown in Figures 2 and 3 . The results of these analyses are summarized in Table 2 and show that both types of salt contain about the same weight percentages of halite and clay. The so-called clean salts appear to have more polyhalite, while the argillaceous salts have more anhydrite and magnesite. Based on these limited data and the strains shown in Figures 2 and 3, damage evolution in WIPP salt is probably not solely related to the clay content of the salt as previously assumed.

TABLE 2

SUMMARY OF X-RAY DIFPRACTION RESULTS FOR WIPP SALT

\begin{tabular}{||c|c|c|c|c|c|c|c|c||}
\hline \multirow{2}{*}{$\begin{array}{c}\text { Test } \\
\text { I.D. }^{\text {(a) }}\end{array}$} & \multicolumn{7}{|c|}{ Compound (Weight Percent) } & \multirow{2}{*}{$\begin{array}{c}\text { Porosity } \\
\phi \\
\text { (percent) }\end{array}$} \\
\cline { 2 - 10 } & Halite & Polyhalite & $\begin{array}{c}\text { Kaolinite } \\
\text { Clay }\end{array}$ & $\begin{array}{c}\text { Illite } \\
\text { Clay }\end{array}$ & Anhydrite & Quartz & Magnesite & \\
\hline \hline TC49 & 92.24 & 5.73 & 2.02 & - & - & - & - & 0.93 \\
\hline TC50 & 96.98 & 3.01 & - & - & - & - & - & 0.37 \\
\hline TC51 & 95.57 & 4.42 & - & - & - & - & - & 0.62 \\
\hline TC52 & 92.04 & 5.22 & 2.15 & - & 0.56 & - & - & 1.44 \\
\hline TC53 & 99.34 & - & - & - & 0.65 & - & - & 1.15 \\
\hline TC54 & 93.37 & - & - & 2.89 & 0.57 & 0.17 & 2.98 & 2.93 \\
\hline TC55 & 92.80 & - & - & 3.68 & 0.52 & - & 2.98 & 3.22 \\
\hline TC56 & 96.32 & - & - & - & 1.24 & 0.30 & 2.12 & 2.20 \\
\hline \hline
\end{tabular}

(a) TC49 through TC52 are "clean" salt; TC53 through TC56 are argillaceous salt.

The mineralogical weight percentages shown in Table 2 for each salt specimen and the specific gravities of these minerals were used to estimate specimen porosity, $\phi$, from specimen mass and volume. Values for specimen porosity are also shown in Table 2 and shown in Figures 2 and 3 next to their respective creep curves. In general, the creep curves are ordered with respect to porosity; i.e., higher creep rates and strain magnitudes correspond directly with higher porosity.

One-dimensional constant head nitrogen gas permeability measurements were performed on three of the four argillaceous salt specimens damaged in the tertiary creep tests. The permeability values determined from these measurements are shown in Table 1 along with the corresponding values for dilatant volumetric strain. Comparison of these dilatant volumetric strain/permeability data pairs with those presented by Pfeifle et al (1998) suggests that the permeability of clean WIPP salt is approximately the same as the permeability of argillaceous WIPP salt for identical levels of damage (i.e., dilatant volumetric strain).

\section{Hydrostatic Compression Healing Tests}

Eight multistage hydrostatic healing tests were performed on damaged WIPP salt specimens, including seven performed on clean salt and one performed on argillaceous salt. The hydrostatic healing stresses were either $1,5,10$, or $15 \mathrm{MPa}$ and the permeant was either nitrogen gas or brine. Healing was defined in terms of permanent reduction in permeability. Permeability versus time data were acquired during each healing stage, and Figure 4 presents the hydrostatic stress and permeability history for a typical healing test on a clean WIPP salt specimen. Permeability data are presented both for the reference confining pressure (i.e., $1 \mathrm{MPa}$ ) and for confining pressures equivalent to the hydrostatic stress imposed during the healing stage. The data show that permeability decreases with time both for the reference confining pressure and the other confining pressures; 
however, the permeabilities measured at the reference confining pressure are always higher than those measured at the higher confining pressures at equal times. This suggests that when the hydrostatic stress is lowered to the reference pressure, some cracks reopen elastically. Table 3 summarizes the results of the eight healing tests and gives the hydrostatic healing stress, permeant, duration of the healing stage, and the permeability values determined both at the beginning and at the end of the healing stage.

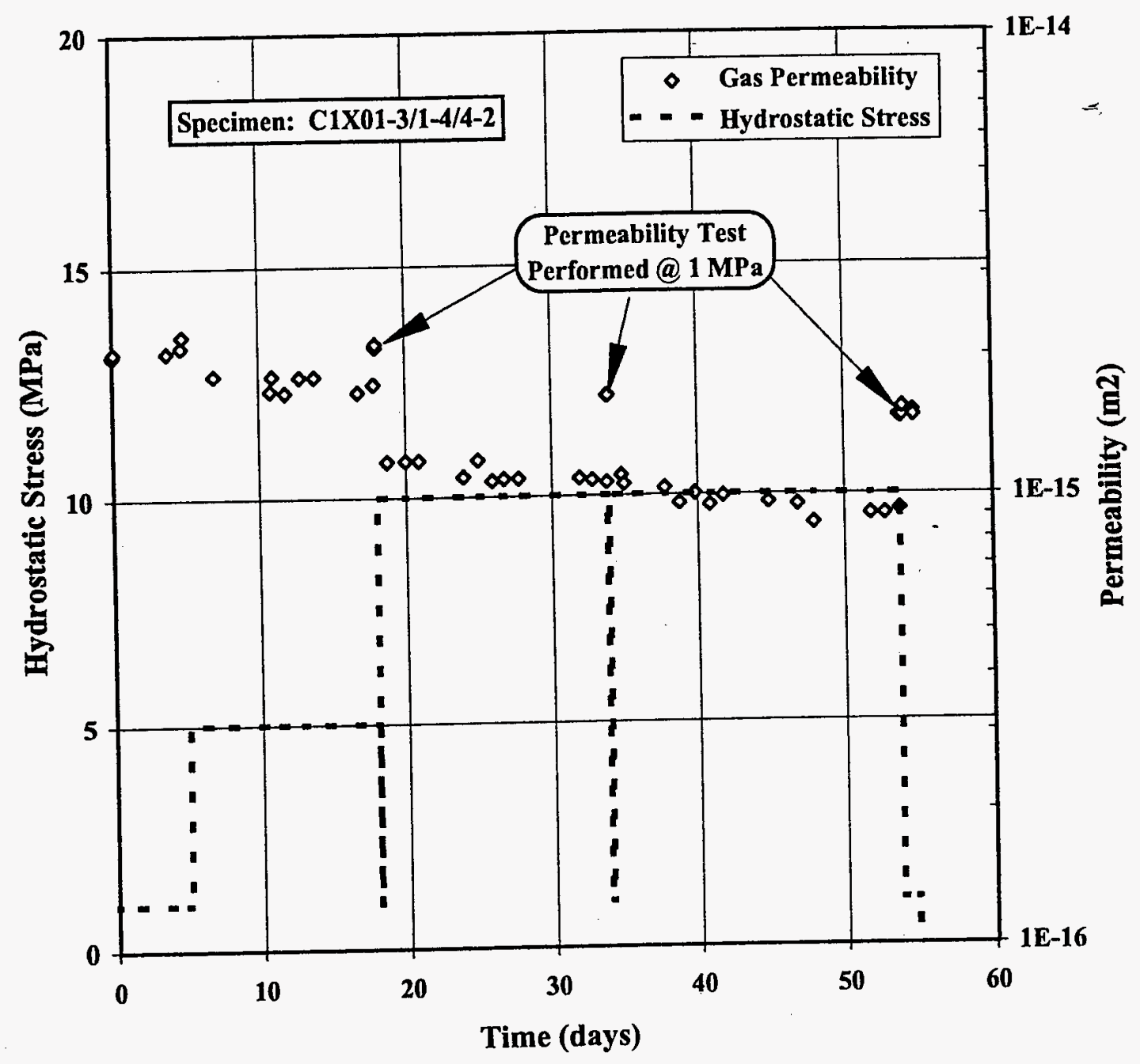

Figure 4: Typical permeability history for a healing test on WIPP salt.

The permeability measurements performed during the hydrostatic compression tests provide a database for estimating the times required to completely heal WIPP salt. Time-dependent phenomena such as healing can be modeled assuming first-order kinetics. A typical first-order kinetics equation for healing, in terms of permeability, $k$, can be expressed as follows:

$$
k=k_{\infty}-\left(k_{\infty}-k_{o}\right) \exp \left(-\frac{t}{\tau}\right)
$$

where $t$ is time and $\tau$ is the time constant determined by fitting the equation to the rate process; i.e., permanent reduction in permeability versus time. The magnitude of $\tau$ determines the rate at which the kinetic process evolves. Process completion times are long or short, depending on whether the magnitude of the time constant is large or small, respectively. The subscripts $o$ and $\infty$ represent the initial and final state of permeability, respectively (i.e., the permeability of the initially damaged and completely healed specimen, respectively). 
TABLE 3

SUMMARY OF RESULTS FOR HYDROSTATIC HEALING TESTS FOR WIPP SALT

\begin{tabular}{|c|c|c|c|c|c|}
\hline \multirow{2}{*}{$\begin{array}{l}\text { Test } \\
\text { I.D. }^{\left({ }^{(a)}\right.}\end{array}$} & \multirow{2}{*}{$\begin{array}{c}\text { Hydrostatic } \\
\text { Stress } \\
(\mathrm{MPa})\end{array}$} & \multirow{2}{*}{$\begin{array}{c}\text { Healing Stage } \\
\text { Duration } \\
\text { (days) }\end{array}$} & \multirow{2}{*}{ Permeant } & \multicolumn{2}{|c|}{ Permeability $\left(\mathrm{m}^{2}\right)$} \\
\hline & & & & $\begin{array}{c}\text { Beginning } \\
\text { of Stage }\end{array}$ & $\begin{array}{l}\text { End of } \\
\text { Stage }\end{array}$ \\
\hline \multirow{3}{*}{ TC48 } & 5 & 21.0 & $\mathrm{~N}_{2}$ gas & $3.17 \times 10^{-15}$ & $3.15 \times 10^{-15}$ \\
\hline & 10 & 10.9 & $\mathrm{~N}_{2}$ gas & $3.15 \times 10^{-15}$ & $2.90 \times 10^{-15}$ \\
\hline & 15 & 28.2 & $\mathrm{~N}_{2}$ gas & $2.90 \times 10^{-15}$ & $1.85 \times 10^{-15}$ \\
\hline \multirow{4}{*}{ TC34 } & 5 & 6.9 & $\mathrm{~N}_{2}$ gas & $3.36 \times 10^{-13}$ & $3.20 \times 10^{-13}$ \\
\hline & 10 & 12.9 & $\mathrm{~N}_{2}$ gas & $3.20 \times 10^{-13}$ & $2.84 \times 10^{-13}$ \\
\hline & 1 & 51.0 & Brine & $3.21 \times 10^{-14}$ & $2.22 \times 10^{-14}$ \\
\hline & 5 & 43.1 & Brine & $2.22 \times 10^{-14}$ & $2.86 \times 10^{-15}$ \\
\hline \multirow[t]{2}{*}{ LCH007 } & 5 & 35.4 & $\mathrm{~N}_{2}$ gas & $5.89 \times 10^{-16}$ & $3.20 \times 10^{-16}$ \\
\hline & 10 & 30.9 & $\mathrm{~N}_{2}$ gas & $3.20 \times 10^{-16}$ & $2.45 \times 10^{-16}$ \\
\hline \multirow[t]{2}{*}{ LCH0O9 } & 5 & 12.9 & $\mathrm{~N}_{2}$ gas & $2.19 \times 10^{-15}$ & $2.13 \times 10^{-15}$ \\
\hline & 10 & 35.7 & $\mathrm{~N}_{2}$ gas & $2.13 \times 10^{-15}$ & $1.49 \times 10^{-15}$ \\
\hline $\mathrm{TC} 42$ & 1 & 44.0 & $\mathrm{~N}_{2}$ gas & $5.43 \times 10^{-14}$ & $5.40 \times 10^{-14}$ \\
\hline LCH011 & 5 & 40.6 & $\mathrm{~N}_{2}$ gas & $1.77 \times 10^{-16}$ & $1.66 \times 10^{-17}$ \\
\hline TC33 & 5 & 62.9 & Brine & $6.20 \times 10^{-15}$ & $1.61 \times 10^{-15}$ \\
\hline TC53 & 10 & 29.5 & $\mathrm{~N}_{2}$ gas & $2.45 \times 10^{-16}$ & $9.2 \times 10^{-18}$ \\
\hline
\end{tabular}

(a) TC53 represents an argillaceous salt specimen.

The time constants determined by fitting Equation 2 to the permeability-time data are summarized in Table 4 and are ordered with respect to healing stress. Large time constants are associated with low healing stresses, while small time constants are associated with high healing stresses. The time required for the healing process to be completed can be estimated by solving for $t$ in Equation 2. These times are also shown in Table 4 and are again ordered with respect to healing stress. These limited data suggest the healing times of WIPP salt will be as little as 1 year or as long as 200 to 300 years, depending on the healing stress; however, adequate permeability reduction can be achieved at earlier times because complete healing is not required to reach the effective or limiting permeability necessary to retard flow.

\section{CONCLUDING REMARKS}

Laboratory tests were performed on clean and argillaceous WIPP salt to characterize damage evolution and healing during tertiary creep and hydrostatic compression healing tests. Nitrogen gas and brine permeability measurements were made during the healing tests, and damage and healing were defined by dilatant volumetric strain and the permanent reduction in permeability, respectively. Strain magnitude and damage were higher for argillaceous salt than for clean salt, and differences may be attributable to porosity rather than mineralogy such as clay content. Permeabilities of argillaceous and clean salts measured at similar damage 
levels are comparable. . Damaged WIPP salt heals under hydrostatic stress conditions and healing can be characterized using simple first-order kinetics. Healing times are shorter for higher values of hydrostatic stress and for brine rather than nitrogen gas. The data suggest that the time required to completely heal the DRZ could be as short as 1 year and as long as 200 to 300 years, depending on the healing stress.

TABLE 4

ESTIMATES OF TIME CONSTANTS AND HEALING TMMES FOR WIPP SALT

\begin{tabular}{||c|c|c|c|c||}
\hline $\begin{array}{c}\text { Test } \\
\text { I.D. }\end{array}$ & $\begin{array}{c}\text { Hydrostatic } \\
\text { Stress } \\
(\mathrm{MPa})\end{array}$ & Permeant & $\begin{array}{c}\text { Time } \\
\text { Constant } \\
\text { (days) }\end{array}$ & $\begin{array}{c}\text { Estimated } \\
\text { Healing Time } \\
\text { (years) }\end{array}$ \\
\hline \hline \multirow{3}{*}{ TC48 } & 5 & $\mathrm{~N}_{2}$ gas & $5,000.0$ & 209.2 \\
\cline { 2 - 5 } & 10 & $\mathrm{~N}_{2}$ gas & 131.1 & 5.4 \\
\cline { 2 - 5 } & 15 & $\mathrm{~N}_{2}$ gas & 62.9 & 2.6 \\
\hline \multirow{3}{*}{ TC34 } & 5 & $\mathrm{~N}_{2}$ gas & 135.3 & 7.3 \\
\cline { 2 - 5 } & 10 & $\mathrm{~N}_{2}$ gas & 109.8 & 5.9 \\
\cline { 2 - 5 } & 1 & Brine & 108 & 5.2 \\
\hline \multirow{2}{*}{ LCH007 } & 5 & Brine & 17.3 & 0.8 \\
\cline { 2 - 5 } & 10 & $\mathrm{~N}_{2}$ gas & 63.1 & 2.3 \\
\hline \multirow{2}{*}{ LCH009 } & 5 & $\mathrm{~N}_{2}$ gas & 130.2 & 4.5 \\
\cline { 2 - 5 } & 10 & $\mathrm{~N}_{2}$ gas & 490.2 & 19.6 \\
\hline TC42 & 1 & $\mathrm{~N}_{2}$ gas & 101.9 & 4.1 \\
\hline LCH011 & 5 & $\mathrm{~N}_{2}$ gas & $5,555.6$ & 274.1 \\
\hline TC33 & 5 & Brine & 55.5 & 2.4 \\
\hline TC53 & 10 & $\mathrm{~N}_{2}$ gas & 10.9 & 0.4 \\
\hline
\end{tabular}

(a) TC53 represents an argillaceous salt specimen.

Sandia is a multiprogram laboratory operated by Sandia Corporation, a Lockheed Martin Company, for the United States Department of Energy under Contract DE-AC04-94AL85000.

\section{REFERENCES}

Brodsky, N.S. Crack Closure and Healing Studies in WIPP Salt Using Compressional Wave Velocity and Attenuation Measurements: Test Methods and Results, 1990, SAND90-7076, prepared by RE/SPEC Inc., Rapid City, SD, for Sandia National Laboratories, Albuquerque, NM.

Chan, K.S., Munson, D.E., Fossum, A.F., Bodner, S.R., Inelastic Flow Behaviors of Argillaceous Salt, International Journal of Damage Mechanics, 1996, 5(3), 292-314.

Dale, T., Hurtado, L.D., WIPP Air-Intake Shaft Disturbed Rock Zone Study, Proceedings of the 4th Conference on the Mechanical Behavior of Salt, 1996, Montreal, Québec, Canada, June, 276-281.

Pfeifle, T.W., Brodsky, N.S., Munson, D.E., Experimental Determination of the Relationship Between Permeability and Microfracture-Induced Damage in Bedded Salt, Proceedings, $3^{\text {rd }}$ North American Rock Mechanics Symposium, 1998, Cancún, Quintana Roo, Mexico, June 3-5. 
$\frac{\text { Report Number (14) SAND }-98-0417 \mathrm{C}}{\text { CONF }-980620 \cdots}$

Publ. Date (11) $\frac{199806}{D O E / E M, X F}$
$\begin{aligned} & \text { Sponsor Code (18) } \\ & \text { UC Category (19) }\end{aligned}$ 